\title{
Research
}

\section{The Evolution of an Ecosystem Approach: the Diamond Schematic and an Adaptive Methodology for Ecosystem Sustainability and Health}

\author{
$\underline{\text { David Waltner-Toews }}^{1}$ and James Kay
}

\begin{abstract}
Over the past $15 \mathrm{yr}$, an international network of researchers has developed and tested a methodology for integrating complex systems theories into sustainable development projects. Drawing on our best theoretical understanding of complex systems and combining it with best practices of community engagement drawn from a wide variety of sources, we have developed a methodology that is theoretically sound and practically effective. AMESH, an Adaptive Methodology for Ecosystem Sustainability and Health, has emerged from, and been tested in, Nepal, Kenya, Canada, and Peru.
\end{abstract}

Key Words: ecosystem approach; research methodologies; adaptive ecosystem management; systems theory; sustainable development; development projects; eco-social systems; diamond schematic; heuristics; narratives; cross-talk

\section{INTRODUCTION}

Managing complex eco-social systems in the service of a sustainable, convivial human society, the underlying agenda of such initiatives as the Millennium Ecosystem Assessment, is itself a complex activity. No straightforward program or method of social or political organization will take us from here to "there." Indeed, we cannot easily define what "there" is. The exact nature of sustainable development, health, integrity, and resilience plus the language used to describe these goals have been and will continue to be the subject of both investigation and debate. This paper describes the development of an investigative process over the past 15 yr by the authors, in collaboration with an international multidisciplinary network of scholars and field researchers.

In 1982, Lee et al. (1982) collated a variety of "ecosystem approaches" to planning and management in the Great Lakes Basin. In 1993, The Ecosystem Approach, a seminal report to the International Joint Commission, drew on Soft Systems Methodology (Checkland 1981, Checkland and Scholes 1990) and advances in hierarchy theory to further enrich and elucidate an ecosystem approach to managing ecosocial systems (Allen et al. 1993). Further work on complexity theory, hierarchy theory, and postnormal science pointed to the need to incorporate multiple perspectives, including those of actors within the system being defined and managed, to approach an understanding of how to not only understand, but also manage, such complex systems (Funtowicz and Ravetz 1993, Kay and Schneider 1994). These ideas of ecosystems with people in them, ecosystem management driven by perspective and preference, and an ecosystem approach that incorporates an understanding of social process as much as ecology provided major challenges to both investigators and practitioners in the rapidly expanding field of what some referred to as sustainable development.

Beginning in 1994, James Kay and his colleagues developed the first of several heuristics referred to by users as "the diamond schematic" (Kay 1994, Kay et al. 1999). Over the next decade, they argued that our emerging understanding of complexity in eco-social systems, which took the form of theories 
of resilience, integrity, and self-organizing, holarchic, open systems (Holling 1986, Kay 1997, Kay et al. 1999), combined with the fundamental assumption that nature itself has no preferences, required policy makers to decide which attractors they preferred. Kay argued that "... the challenge facing the practice of environmental management is to learn how to work with these self-organizing processes in a way which allows us to meet our species needs, while still preserving the integrity of ecosystems, that is to say the integrity of the selforganizing processes ..." (Kay 1994). The "diamond" in the diamond schematic was the nexus in which ecological understanding and sociocultural preferences met and interfaced with policy makers and managers.

In 1996, the authors of this paper and several other members of an emerging international network of scholars proposed a research methodology that embedded the modeling and framing of complex eco-social systems into a management and assessment process (Rowley et al. 1997). That is, we proposed that, in the context of uncertainty and complexity, policies were essentially hypotheses and management activities were tests of those hypotheses.

Since that time, this network of researchers has collaborated with local communities to test and enrich these ideas in Peru, Kenya, Canada, and Nepal. The close collaboration between field practitioners and theoreticians made it possible to strengthen both the theory and the practice of this emerging ecosystem approach. Some might prefer to call this an eco-social or adaptive management approach; however, Kay saw this clearly as a natural progression of earlier ecosystem approaches. The new framing of these approaches simply took seriously both the uncertain nature of our understanding of complex reality and our roles as a species within it (see, e.g., Kay et al. 1999). Based on our first decade of experiences in various diverse contexts around the world, this methodology appears to be robust and effective in both generating new understanding and promoting the goals it seeks to understand. It is thus both a research methodology and a management methodology.

Many of the case studies cited in this paper, as well as some of the theoretical and governance issues raised, are described in considerably more detail in Waltner-Toews et al. (in press).

\section{THE BASIC HEURISTIC}

An adaptive ecosystem approach to sustainability and health assumes that a sustainable society maintains itself in the context of the larger ecological system of which it is a part. Within the dynamics of eco-social complexity and the uncertainty this generates, we are faced with finding our way through a foggily perceived landscape rather than charting a scientifically determined course to a known end point. Throughout the 1990s, author J. J. Kay, working with many colleagues and students at the University of Waterloo, developed a schematic for bringing together some of these strands of theory and practice. This framing of the process is known as "the diamond schematic," and the central diamond is the area in which the understanding of the ecological system unites with that of the sociocultural system in a set of choices for human agents (Fig. 1).

In this framing of sustainable development research, the scientist's role shifts from providing predictive statements for policy makers to providing decisions makers and the community with an appreciation of how the future might unfold through narrative descriptions or scenarios (Kay 2000). Through systemic framing of the issues as self-organizing, holistic, open systems (Kay et al. 1999), science informs society about known ecological constraints and possibilities (top left-hand box in Fig. 1).

The dynamics and structures of such selforganizing, holarchic, open (SOHO) systems are well described elsewhere, sometimes using different terminologies to refer to similar phenomena (e.g., Kay et al 1999, Boyle at al. 2001, Gunderson and Holling 2002, Walker et al. 2002). We believe that the language of holons and holarchies derived from Koestler acknowledges the long-standing theoretical work in this field and provides a useful, clear shorthand for describing the nature of units in a nested hierarchical nature (Koestler 1969, 1978, Kay et al. 1999, Giampietro 2004:32-33). In brief, any eco-social unit, e.g., person, family, pond, watershed, can be seen both as a whole, with its own internal rules and interactions, and as part of multiple, selfperpetuating nested hierarchies. The unit itself, referred to in thermodynamics as a dissipative system, is called a holon. "A nested adaptive hierarchy of dissipative systems can be called a holarchy ... " (Koestler 1969:102). The description 
Fig. 1. One version of the "diamond" heuristic of the ecosystem approach adapted from Kay and Boyle (1999). It shows how scenarios, visions, and managing for sustainability emerge from the integration of ecological and sociocultural understanding. Other versions of this figure can be accessed at www.jameskay.ca.

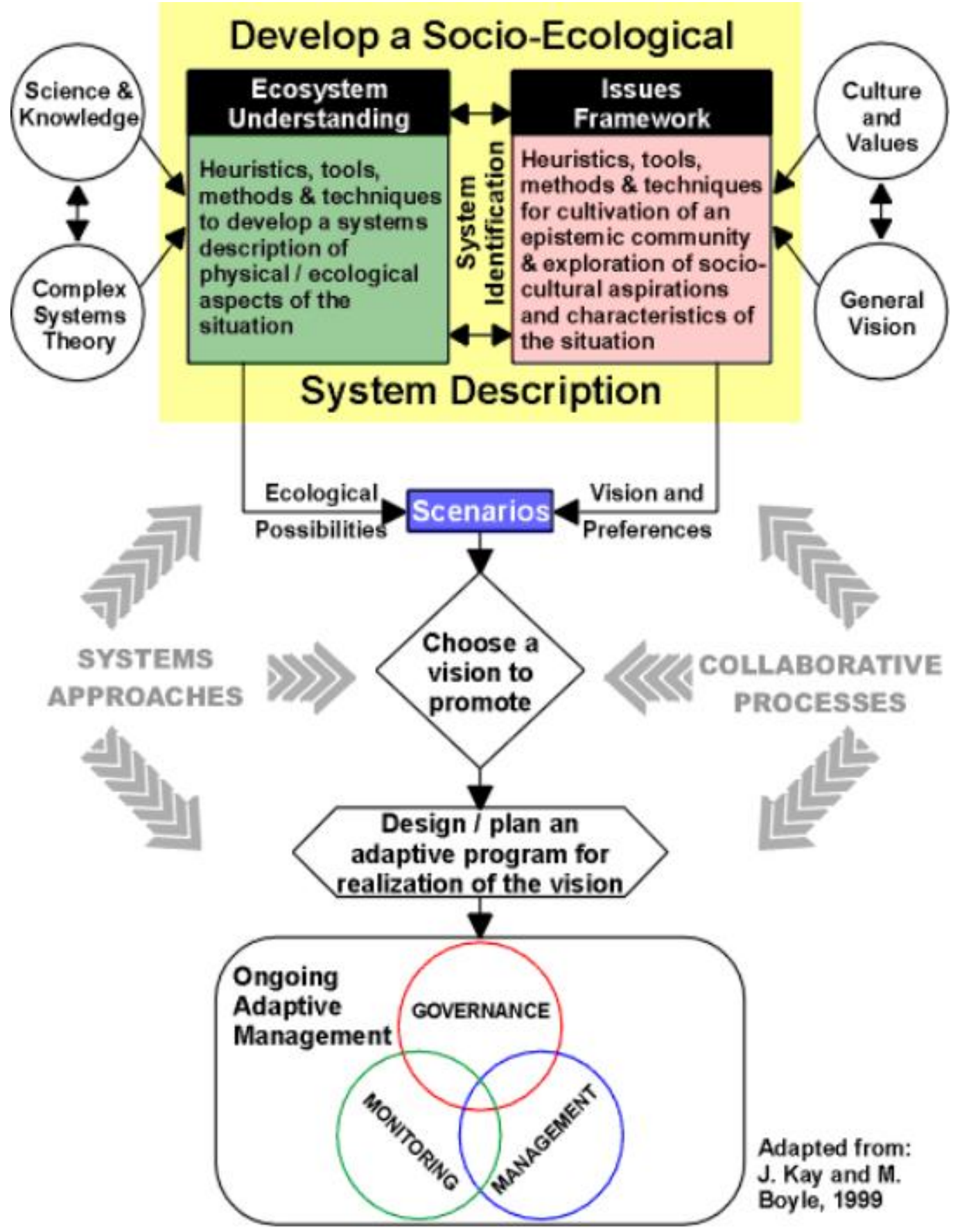


of such systems is observer-dependent (Allen and Hoesktra 1992).

Holling (1986), Holling et al. (2002), Ulanowicz (1997), Kay et al. (1999), Boyle et al. (2001), and others have provided a variety of heuristics and a variety of terms for describing self-organizing processes at different scales. Within the diamond schematic, these systemic representations of complexity are, in turn, informed by the images people provide of how they would like to see the landscape of human and natural ecosystems coevolve (top right-hand box in Fig. 1.) A dialogue must ensue (the diamond box in Fig. 1) that explores the desirable and the feasible and reconciles them in a vision of how to proceed. Scientists inform this dialogue by suggesting a range of possible future narratives. These emerge and evolve as scientists engage with other participants. Having agreed to a tentative community vision for the future, the next phase is to design an adaptive program for the realization of the vision.

This adaptive program consists of a plan and an infrastructure for the following three activities:

1. Governance, which involves the continuing process of learning, re-visioning, resolving trade-offs, and planning by the parties to adapt to the unfolding situation. This entails the ongoing evolution of governance arrangements. Virtual governance of this type has occurred in the Great Lakes basin with the emergence of community-based initiatives that organize to focus on specific elements of the landscape such as watersheds or bays.

2. Management, which translates the vision into reality. It involves the development and implementation of strategies to promote or discourage specific forms of self-organization in the context of the communal vision and plan. This means maintaining the context for self-organizing systems, rather than intervening in the system in a mechanical way (Kay and Schneider 1994, Kay et al. 1999, Boyle et al. 2001). Maintaining the context involves the identification of external contextual changes, flows into and from the system, and feedback loops that are to be encouraged and discouraged. Generally speaking, management concentrates on the relationship between humans and natural ecosystems and on guiding the human side of the relationship.

3. Monitoring, which is the activity of observing the human and natural systems and synthesizing those observations together into a narrative that describes how the situation has actually unfolded and how it might unfold in the future. This narrative is used as the basis for governance and further management, that is, for learning, re-visioning, and adapting human activities as the human and natural ecosystems co-evolve as a self-organizing entity.

In this adaptive ecosystem approach, monitoring, governance, and management make up a triad of activities that are carried out in the context of a framework of issues of concern to humans and an explicit conceptual model of the ecologicaleconomic system. Taken together, the framework of issues and the conceptual model provide the focus for the discussion of sustainability. By furnishing a means for informed resolution of the trade-offs necessary to sustain the health and integrity of the eco-social system, the activities of monitoring, governance, and management, carried out in concert, chart the course to sustainability.

\section{ADAPTING THE HEURISTIC: LESSONS LEARNED FROM CASE STUDIES}

By the early 1990s, we were well aware of many of the basic elements of an ecosystem approach, such as the necessity for multiple perspectives within a transdisciplinary framework and the need to accommodate social as well as ecological understanding. From 1993 to 1998, the Agroecosystem Health Project, a major interdisciplinary Canadian initiative to define agricultural landscapes and communities systemically, incorporated some of the ideas represented in the diamond schematic; however, the perspectives accommodated were limited to professional expertise across a dozen disciplines, and the process relied on expert peer review (Smit et al. 1998). This was unsatisfactory from both theoretical and practical points of view: large amounts of nonexpert understanding were marginalized, and the information generated did little to either enlighten or mobilize the ecosystem 
Fig. 2. An integrated conceptual framework for research into tropical agroecosystems based on complex systems theories (Rowley et al. 1997).

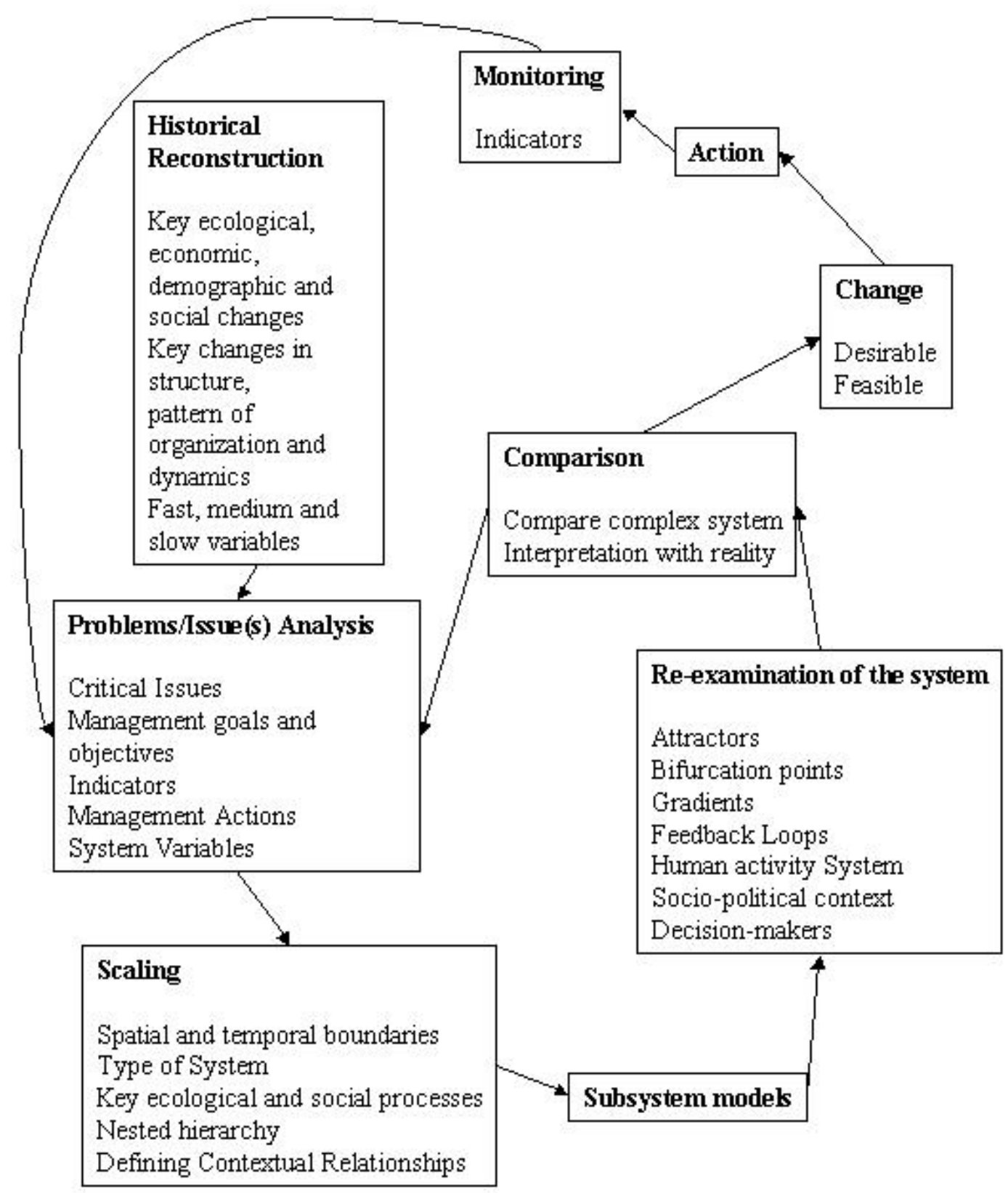


managers, who included farmers and other rural residents as well as agricultural policy makers. Furthermore, this Canadian project did not sufficiently take into account cross-scale dynamics within which particular holons of interest such as farms were characterized. It was not clear to us how, in theory and in practice, we could simultaneously accommodate the dynamics of farms as economic units within a larger agri-food system, ecological units within waterheds, and social units with rural communities.

Drawing on lessons learned from the Agroecosystem Health Project, a team of researchers lead by Gilberto Gallopin of the Centro Internacional de Agricultura Tropical (CIAT) initiated a project on the development and application of an integrated conceptual framework to tropical agroecosystems based on complex systems theories (Rowley et al. 1997). The project focused on the Ucayali region of the Peruvian Amazon, around the major city of Pucallpa. Although the research gave stakeholders an important role, they were still viewed more as consultants rather than as necessarily inherent to the process (Fig. 2).

We assumed, incorrectly, that we could compare the heuristic models we developed from secondary data, which included resilience models, Holling's "four-box," catastrophe representations, and nested holons, with some independent, objective version of reality to determine their "correctness." On the positive side, we did specify and expand on several of the steps in explicit terms of complex systems, list out "guiding questions" for each of the steps, and make the process close in on itself, which is not the usual outcome when linear research hypotheses are tested. We also identified complementary roles for expert researchers and local stakeholders, and paid careful attention to the selection of local research partners. In the process, we discovered that the initial stakeholder-partner group we had selected, which itself had been created through a previous unrelated research initiative, represented mainly academics and business people living outside the communities being studied. This work thus underlined the need for researchers to be critically self-reflective about the invocation of "stakeholders" and to question the interests of those stakeholders in the systems being studied.

Although we drew theoretically on complex systems theory and thermodynamics to understand the dynamics of the situations we were investigating, the management side of this emerging process drew heavily on soft systems methodology, social systems design, interactive planning, Beer's viable systems model and team synergy, participatory action research, and adaptive management. We also consulted the large body of literature on thermodynamics, multicriteria analysis, and societal physiology, some of which has only recently been summarized (Walters 1986, Pretty et al. 1995, Kay et al. 1999, Giampietro 2003; Bunch et al., in press).

A follow-up research project in the same geographic area focused on links between health, biodiversity, and natural resource use (Murray et al. 2002). In this second phase of the work, representatives of local indigenous groups and women's organizations took their place alongside workers in government ministries and researchers attached to institutions that included Peruvian and Canadian universities as well as CIAT. This facilitated the integration of local experiential knowledge with data derived by more conventional scholarly inquiries such as surveys, interviews, focus groups, anthropometric measurements, and testing of biological specimens.

Concurrent with the research in the Peruvian Amazon, two other projects, one in the Kenyan highlands (Gitau et al. 1998, 2000) and one in Nepal (Waltner-Toews et al. 2005), were exploring the same methodological territory (Waltner-Toews et al. 2003). The Kenyan research team led by Gitau found that the mobilization of local stakeholders into the research process almost immediately generated a demand for action, so that well-laid-out pathways for the orderly accumulation and assessment of knowledge could at best serve only as guides to ensure that important considerations were not overlooked. This also emerged as an issue in Peru. In both cases, having well defined holarchic models was important; it was not enough to define household or village dynamics, but links across scales and across social and ecological perspectives also had to be included. Thus, problems identified at the village level could be related both to household and individual dynamics as well as to larger regional political and ecological contexts. This enabled the team not only to better understand the problematic situations but also to identify potentially effective routes to respond to them.

Second, it became apparent that indicators for sustainability could not be defined independently of 
goals. In Kenya, indicators used by villagers and farmers were often quite different from those used by researchers, because their goals were different. Researchers therefore had to be defined as a separate category of stakeholders with their own interests, goals, and indicators for measuring progress. Farmers and villagers worked on different time frames, with different resources, and had different requirements than researchers.

Gitau, working with Kenyan villagers, also developed techniques for creating influence diagrams that linked all the elements of interest to the participants in the research. These complex "spaghetti diagrams" were used by villagers to identify strategies to achieve desirable ends while accounting for known feedback loops, and by researchers to model the dynamics of known variables in the system (Gitau et al. 1998).

Drawing on the work of Gitau, we developed a more complete schematic for sustainability research that explicitly acknowledged the different needs, skills, and resources of researchers and stakeholders, and further refined the use of influence diagrams drawn in collaboration with stakeholders. We also reassessed our earlier practice of too clearly separating the roles of academic researchers and local participants. If knowledge and understanding are not the exclusive domain of academia, then the important process questions relate to the skills of the participants and the quality of information, rather than to maintaining predefined roles.

Funtowicz and Ravetz have argued that, in postnormal science, where facts are uncertain or in dispute and conflicts over values or epistemologies interact in unpredictable ways with decision making, quality displaces achievement of truth or "facts" as the fundamental guiding principle. Quality is a self-critical, pragmatically defined "fitness for purpose" in relation to some higher good; monitoring of quality is a social progress that itself must be subject to quality control processes (Funtowicz and Ravetz 1990, Ravetz 1999). Hence, the quality of the information generated by both scholars and lay people in a sustainable development research and/or management project relates not just to outcomes, i.e., the achievement of collective visions and goals, but also to the processes by which decisions are made regarding collective visions and goals. In this public science, the main challenges involve the transparency, critical thinking, and public counterchallenges that differentiate science from religious or corporate pronouncements. One of great challenges faced by participants in such a process is how to accommodate fundamentally different epistemologies (Berkes and Folke 1998).

The project in Nepal, which evolved through several stages over the decade of the 1990s (Waltner-Toews et al. 2005), brought to the fore two techniques that enabled debate across these epistemological divides, a process that Kay has referred to as "crosstalk." One of these was the use of the type of collaboratively drawn influence diagrams mentioned above. In Nepal, we introduced these diagrams rather late in the process and based them on comprehensive narrative reports compiled by community researchers. The innovation in this case was that separate diagrams were created for each major issue such as street waste/garbage disposal and water quality from the perspective of each major stakeholder group, e.g., street sweepers, butchers, street vendors. These multiple diagrams were then combined to create a richer picture of the webs of interaction and, just as importantly, the perceptions of causes by different stakeholders. Both the single perspective and the combined drawings were presented at a workshop for the community participants, who used them as a basis for planning future initiatives.

The other tool to facilitate cross-talk was the use of narratives. Narratives are central to how we structure our understanding of how complex systems unfold over time (Kay 2000). The role of narratives in human thought processes and actions, including in science and management for eco-social sustainability, has only recently been pursued by scientists, but has been discussed in many other domains of inquiry, including law, anthropology, and community development (see, for instance, Kay 2000, Allen et al. 2001, Bruner 2002, Hogan 2003, White 2003, Olsson et al. 2004). In Nepal, by asking participants to recount the stories they would like their children to tell about them, we were able to foster debate, essentially about future scenarios and their relationships to current activities. More formally, Allen has recently proposed that narratives are required to structure our understanding of how multilevel complex systems unfold over time (T. H. F. Allen, unpublished manuscript). 
Fig. 3. Adaptive Methodology for Ecosystem Sustainability and Health, integrating researchers as stakeholders.

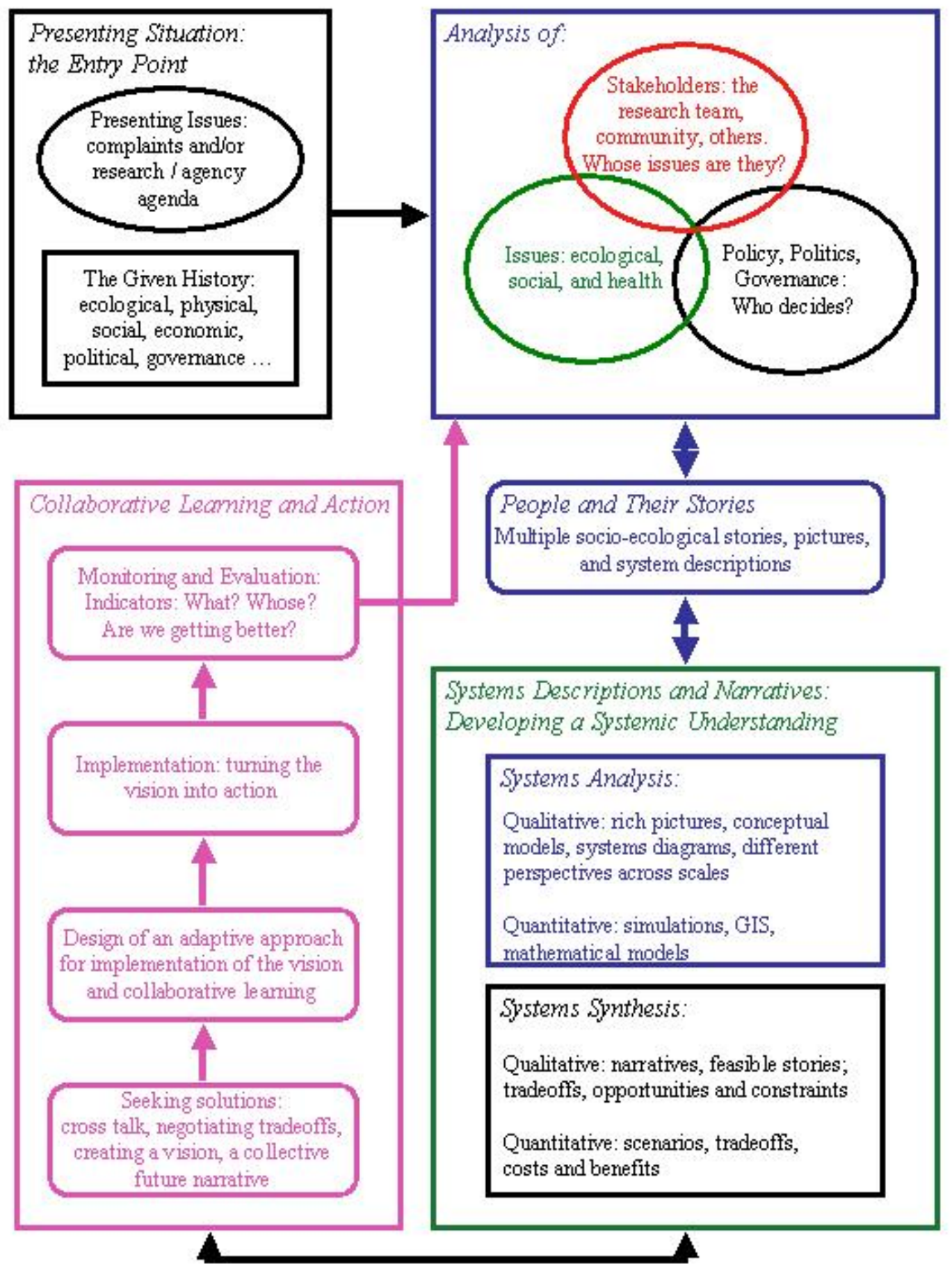




\section{APPLYING THE HEURISTIC: A NEW SYNTHESIS}

As we put together the basic characteristics of complex systems such as multiple incommensurate perspectives, feedback loops, and nested hierarchies, and faced the methodological challenges of these various projects on the ground, a more complete research methodology emerged. We integrated researchers into the process more completely and recognized our own role as stakeholders whose characteristics were just as unique as those of the participants from the local community (WaltnerToews et al. 2004b). In this process, which we termed an Adaptive Methodology for Ecosystem Sustainability and Health (AMESH), the expanded peer group includes both scholarly researchers and local citizens. At the same time, in the manner of a true peer group, all forms of knowledge become open to mutual challenge. Although stakeholder participation and the use of a plurality of perspectives and methodologies were implicit in the research process we proposed in the mid-1990s (Fig. 2), these components were made explicit in AMESH (Fig. 3).

Based on the work in Kenya, Nepal, and Peru and on complementary work in Canada not discussed here, we identified the following series of relevant components to an effective ecosystem approach:

1. The situation is brought to someonel's attention, often because the local people, researchers, or some third-party agency perceives a problem.

2. The "responders" attempt to understand the situation systemically by incorporating a variety of multiscalar social and ecological perspectives.

3. Some combination of local stakeholders and researchers identifies system-based alternative courses of action at various scales and from various perspectives.

4. Stakeholders choose a course of action, develop a plan that incorporates a collaborative learning system, begin implementation, and ensure that governing, monitoring, and management co-evolve with the changing situation.

5. Outside investigators have the responsibility to try to understand the system, the process, and how the process interacts with, and perhaps determines, our understanding.

AMESH draws on a set of guiding principles rather than prescriptive actions. Methodological processes are described in terms of sets of activities, and these are elaborated in terms of guiding questions. The four guiding principles that arise from an understanding of self-organizing, holarchic (SOHO) eco-social systems are as follows:

1. Self-organization, which may incorporate threshold effects and "creative destruction" (see Holling 1986, Kay et al. 1999, Boyle et al. 2001, Gunderson and Holling 2002), occurs within holons.

2. There are hierarchical/holarchical crossscale feedbacks.

3. The first two principles compromise our ability to predict.

4. Therefore, we must use methodological pluralism and incorporate multiple perspectives from all legitimate stakeholders

These guiding principles may be depicted in terms of a variety of heuristic, systemic models of SOHO systems. These have been described in some detail in other publications (Boyle et al. 2001; WaltnerToews et al., in press). Two figures from a series of such diagrams will illustrate this (Figs. 4 and 5). Ecological systems provide the biophysical context and the flows of exergy, material, and information that are required by the self-organizing processes of the societal systems (Fig. 4). Societal systems can and do alter the structures in ecological systems, for 
Fig. 4. A model of a single holarchical level of ecosystems and their interactions. Dotted lines represent one system forming the context for another. The arrow across the bottom represents direct societal influence on the ecological system, i.e., changing structure. The larger arrow across the top represents indirect societal influence on the ecological system, i.e., changing the context for the ecological system that cascades down to change the societal system.

Context

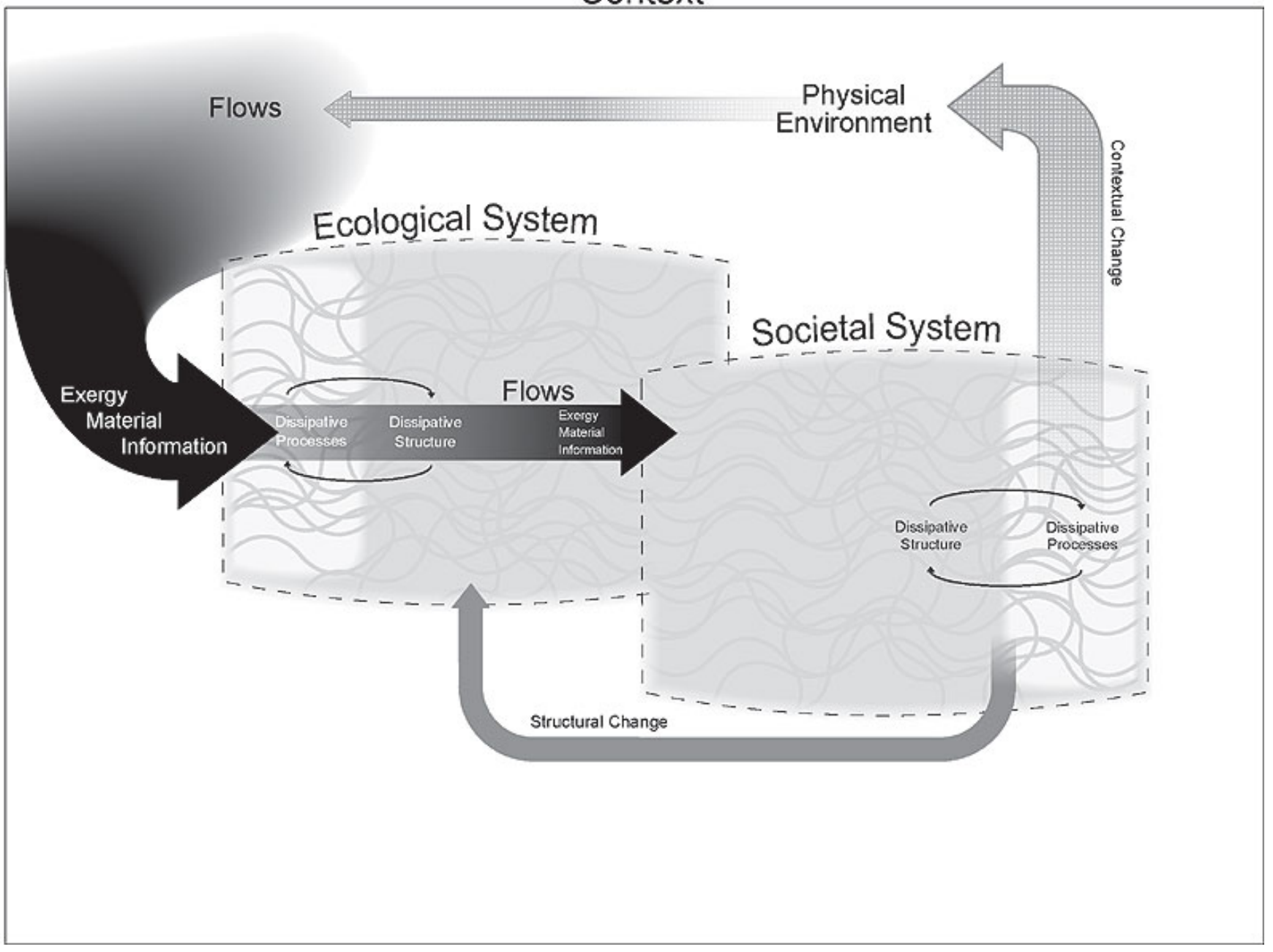

example, through harvesting trees or building or removing dams or roads. Changes in the ecological structure alter the context for the societal systems. Societal systems not only change the structure of the ecological systems, but also the context for the self-organizing processes of ecological systems, for example, by changing the drainage patterns into a wetland or paving a large area, which creates a heat island effect that changes the local microclimate for a woodlot. Changes in ecological process can alter the ecological structure and, consequently, the context for societal systems.

Figure 4 applies to one scale of observation. However, the kinds of resilience, integrity, and health that interest us when we pursue research into sustainable development can only be understood in 
Fig. 5. An example of components and interactions over three holarchical levels beyond the individual. The "stacked deck" effect is a reminder that each level is made up of a conglomeration of defined systems, i.e., that many species together comprise an ecological community and many communities together form the local landscape. It is the aggregation of these local landscapes that makes up the landscape mosaic of a region such as a province or state. On the societal side, families and businesses comprise neighborhoods. Municipalities are made up of neighborhoods, and, finally, the province/state is politically divided into municipalities and counties. Note that this diagram demonstrates only one possible way of parsing the system.

Context

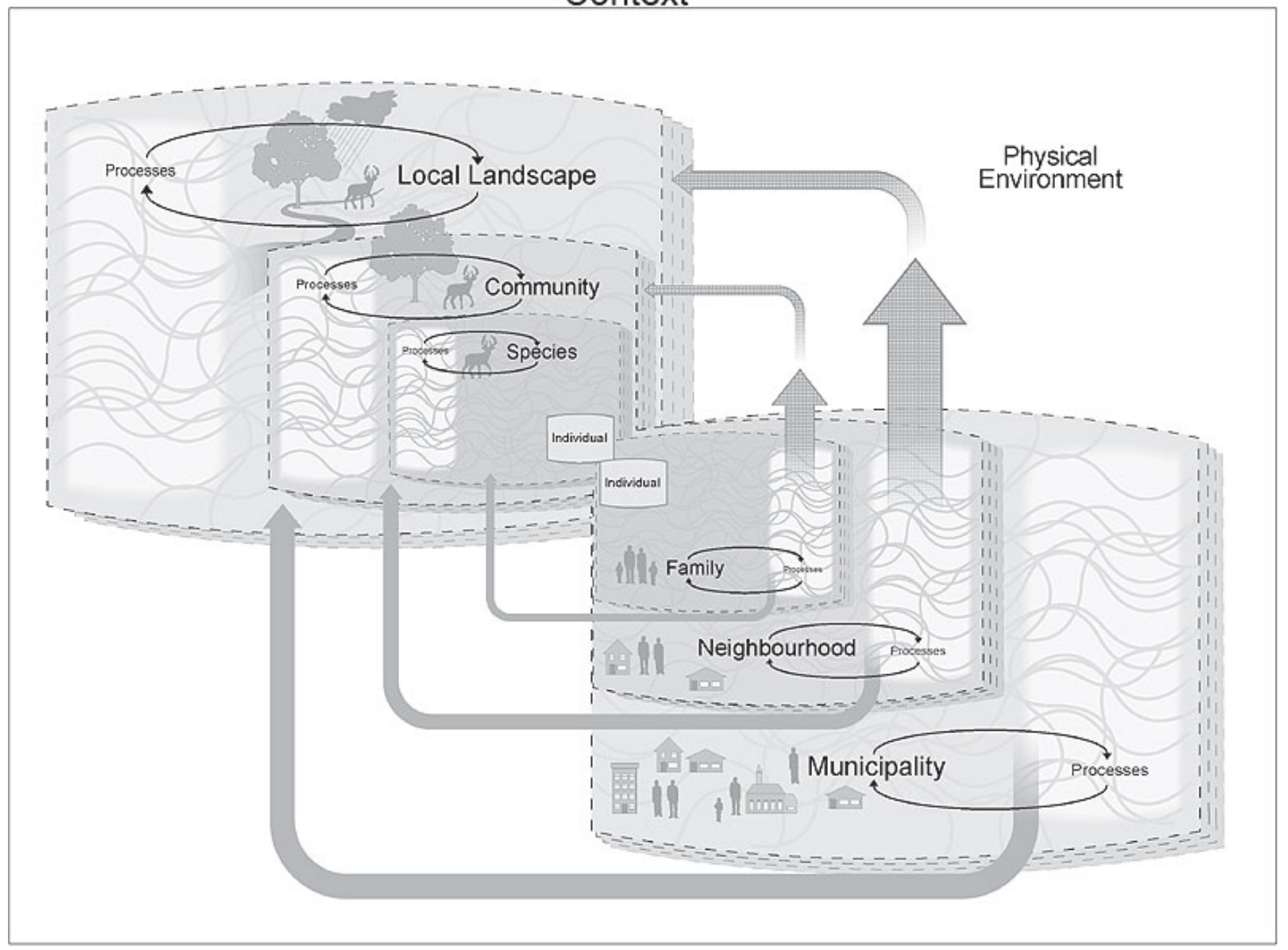

terms of nested holons. Figure 5 illustrates this idea of nesting. On the ecological side, for instance, the hydrological cycle may be viewed as a process of a subwatershed. The structures that make up the subwatershed are the ecological communities, e.g., woodlots, wetlands, open fields, etc. The communities in turn are made up of species. On the societal side, municipalities rest on the local landscape. These in turn are made up of neighborhoods, which are made up of families, businesses, and, ultimately, individuals.

A subwatershed may define the context for the local municipality. However, the municipality directly 
modifies the ecological communities in the subwatershed and thus its own context. Adjacent ecological communities also form part of the context for local neighborhoods. However, as we discussed in the previous section, the local neighborhood is capable of influencing ecological communities through direct structural change such as harvesting wood from a woodlot or altering the context for an ecological community, e.g., changing drainage patterns into a wetland.

AMESH suggests that such complex eco-social interactions can only be understood through the integration of many diverse and often differing perspectives. To gather and weave together these multiple perspectives, AMESH encourages the use of a range of qualitative and quantitative inquiry and analytical methods. Additionally, AMESH acknowledges the fundamentally important role that local people play in any endeavor to address ecosystem sustainability and health and supports the full participation of local people and the inclusion of nonexpert perspectives to shape and inform our understanding of the ecosystem. Although the local perspective is critical to AMESH, the larger context in which the local is embedded is equally important. In the various projects on which we have worked, the nested context has been an important part of both the research and the constraints to the work.

Within AMESH, researchers and practitioners are encouraged to look for and understand system feedback and the emergence of self-organization. The iterative nature of this process and its multiocular assessments mean that the unpredictability and uncertainty of eco-social systems, with the potential for dramatic flips, can be more easily accommodated than in more conventional approaches.

Although there is no single prescribed course of action for AMESH, we can describe it in five broad categories of action (Fig. 3). Each of these has associated with it a set of guiding questions. The guiding questions and the process itself have been set out in detail elsewhere, both in general terms and in relation to specific research sites (Waltner-Toews et al. 2004b). The techniques used to answer the guiding questions have been appropriate to the questions asked and have included the examination of historical records; tests of fecal, blood, and water specimens, both in the field and in laboratories; personal interviews; visual inspection; focus groups; remote sensing; and GIS-based, food web, statistical, and simulation models. Not all questions are appropriate for all cases, and some require more money, time, or other resources to answer; we have found that communities usually move ahead with policies and plans based on early and incomplete information. For researchers, the important point is to use these initiatives as occasions for learning, rather than frustrations of plans; in other words, the research plans need to be adaptive.

The first several components are rather straightforward. Although many scientists tend to be most comfortable with analytical activities and the gathering of supportive data, enough links have been developed between those doing both participatory investigations and qualitative and quantitative inquiries into governance and the like that these activities are neither controversial nor new.

For us, the main challenges lie in the use of narratives and in the fifth component: collaborative learning and action. Because there are no definitive experiments and no final, unassailable truths in the field of sustainability, collaborative learning and action are central to an implementation of the approach we have developed. For some researchers, this is problematic, because we incorporate elements of what has been viewed as management into the research itself. In AMESH, as in the diamond framework, every policy initiative is a hypothesis, and every implementation or management program becomes a test of that hypothesis. Because of the complex nature of the issues with which we are dealing and with people, i.e., the observers, inside the system being studied and managed, proposed solutions must be negotiated based on the trade-offs identified in the system investigations. As researchers, we ask questions about how different perspectives conflict with, or complement, each other, and what kind of sustainable futures might be feasibly designed. Moving from visioning and designing to implementation, we can ask specific questions about the logistics of management.

As in all good research, the process requires us to monitor changes, with a view to adapting our interventions in the light of changes in context and outcome. However, when there are multiple stakeholders with varying interests in the outcomes, we are faced with questions about what the indicators actually measure and who "owns" them, that is, who thinks they are important and is likely 
to take action on them. If measuring certain indicators requires very expensive technical equipment and/or takes a long time, then such measurements are not likely to be useful for day-today decision making by local householders, farmers, or businesses. They may, however, be useful for detecting long-term trends and setting policies. On the other hand, if not dealt with carefully and self-critically, some of these indicators may be used by governmental and quasigovernmental agencies to promote centralized control mechanisms and undermine local initiatives. At the local household and community levels, we need indicators that are measured and understood with relative ease, so that people will own them and act on them. There is no one correct set of indicators, because they reflect both our understanding of the complex reality and our goals.

\section{CONCLUSIONS}

The research process we arrived at is similar to that proposed by Walker et al. (2002), which emerged from their consideration of resilience and socialecological complexity. The fact that our networks worked independently and drew on different case material gives us some confidence that such a process may be robust and have general applicability.

One important difference between the two processes appears to be with regard to the role of stakeholders. According to a typology of participation, the role of stakeholders in the process of Walker et al. appears to fit into the category "participation by consultation," whereas in AMESH it is closer to "interactive participation" (Pretty et al. 1995).

One reason for this may be that our work was informed not only by issues arising from the adaptive management of ecological systems, but also, and perhaps more directly, by the challenges faced when implementing sustainable community development projects in economically impoverished countries. In any case, the nature and extent of local community participation and the roles of alternative world views in arriving at a process remain a major challenge to all of us.

In our case, we found that the ecosystem approach we have developed changed not only our understanding of the places we were studying but also the academic researchers, our governmental and nongovernmental collaborators, and the communities with whom we worked. In Peru, the researchers' perspective changed from one in which they saw only a forested landscape with rivers running through it, troubled by cattle and logging, to one that also viewed that landscape as a watery floodplain with trees growing in it, inhabited by people who lived on fish. This facilitated engagement between government and local indigenous groups and changed the nature of the initiatives being proposed to promote health and sustainable use of the landscape. In Nepal, an improved understanding of the complex social dynamics among castes, economic and occupational classes, religious groups, and governmental and nongovernmental agencies generated opportunities for some creative solutions. Ward governments were able to restrict slaughtering areas and replant riverbanks, religious groups rehabilitated naturally flowing artesian fountains, and local volunteer "clubs" were able to promote recycling and garbage collection programs. In Kenya, the links between environmental management issues and social and economic activities clarified some possibilities for improvement that had not previously been obvious. Villagers developed, implemented, and found funding for integrated water management programs, and women for the very first time found themselves in respected positions of governance at the local level.

Finally, it appears that this work fostered the resilience and adaptive capacity of the eco-social systems within which we collaborated. In Nepal, the commitment to local action and engagement has so far survived serious threats from the political breakdown and the reframing by authorities of a long-standing civil conflict as a "war on terror." The nonuniversity-based Nepalese scholars and community researchers with whom we worked are currently working with those communities on a public education initiative. Initiatives begun in Peru and Kenya also appear to be self-sustaining. In each area, the social organizations that emerged from our engagements, along with their monitoring and response capabilities, appear to be ongoing and learning from their own experience. Time will tell, of course, whether this will continue. Given some weakness in these project-driven activities on governance issues and in the face of massive contextual changes in how problems are framed and dealt with after September 11, 2001, we withhold some judgment in this matter until we can get better information about how the systems are unfolding 
over time. The implementation and assessment of initiatives whose aim is to understand and foster sustainable development do not lend themselves well to 3- or 5-yr project cycles.

We are currently using AMESH to investigate the responses of several Canadian prairie communities to extreme weather events (www.eccho.ca). In this case, we are more explicitly incorporating insights into resilience and vulnerability generated by the Resilience Network. We expect that this will make the work more robust and theoretically generalizable. We are also working with some Cuban communities to examine eco-social dynamics related to ciguatera fish poisoning (Lehane and Lewis 2000), and using some explicit insights from hierarchy theory and integrated placebased management to further our understanding there.

Ultimately, what we seek is a way of integrating our ways of knowing with our ways of doing. By ways of knowing, we mean not just what has been considered science in conventional terms, but also different kinds of knowledge that reflect different epistemological stances. Both the diamond schematic, as a way of framing sustainability issues, and the Adaptive Methodology for Ecosystem Sustainability and Health, as an approach to research and management, appear to provide coherent, self-reflective ways to accomplish this.

Responses to this article can be read online at:

http://www.ecologyandsociety.org/vollo/iss 1/art38/responses/

\section{Acknowledgments:}

Many of the projects described in this work were funded by the International Development Research Centre in Ottawa. The ideas in this paper represent our synthesis and précis of a decade of research by members and associates of the Network for Ecosystem Sustainability and Health, the Dirk Gently Gang, NUSAP.net, and Liphe4.org (WaltnerToews et al. 2004a). We cannot name all our associates but would especially like to thank Thomas Gitau, D. D. Joshi, SAGUN, Tamsyn Murray, Cynthia Neudoerffer, Martin Bunch, and Michelle Boyle. Also, a very, very special thanks to Julian van Mossel-Forrester for working closely with the authors to complete the SOHO diagrams
(Figs. 4 and 5) during the last months of James Kay's life. Others may well see this work differently, and interpret it differently. Because this manuscript was finalized after James Kay died, whateverfaults there are in this paper can be laid at the door of the lead author. This paper is dedicated to the memory of James Kay, who died in May 2004 at the age of 49, and of Thomas Gitau, who died in March 2005 at the age of 38. Both were brilliant researchers and wonderful colleagues who are dearly missed.

\section{LITERATURE CITED}

Allen, T. H. F., B. Bandurski, and A. King. 1993. The ecosystem approach: theory and ecosystem integrity. Report to the Great Lakes Advisory Board. International Joint Commission, Ottawa, Canada, and Washington, D.C., USA.

Allen T. H. F., J. A.Tainter, J. C. Pires, and T. W. Hoekstra. 2001. Dragnet ecology_-Just the facts, Ma'am": the privilege of science in a postmodern world. Bioscience 51:475-485.

Berkes, F., and C. Folke, editors. 1998. Linking social and ecological systems. Cambridge University Press, Cambridge, UK.

Bruner, J. 2002. Making stories: law, literature, life. Farrar, Straus and Giroux, New York, New York, USA.

Bunch, M., D. McCarthy, and D. Waltner-Toews. 2005. Learning by doing: systemic participatory approaches to management. In D. Waltner-Toews, J. J. Kay, and N. M. Lister, editors. Uncertainty and managing for sustainability. Columbia University Press, New York, New York, USA, in press.

Checkland, P. B. 1981. Systems thinking, systems practice. John Wiley, Toronto, Canada.

Checkland, P., and J. Scholes. 1990. Soft systems methodology in action. John Wiley, Toronto, Canada.

Funtowicz, S. 2001. Peer review and quality control. Pages 11179-11183 in N. J. Smelser and P. B. Baltes, editors. International encyclopedia of the social and behavioural sciences. Elsevier/Pergman, 
Oxford, UK.

Funtowicz, S., and J. Ravetz. 1990. Uncertainty and quality in science for policy. Kluwer Academic, Dordrecth, The Netherlands.

Funtowicz, S., and J. Ravetz. 1993. Science for the post-normal age. Futures 25:739-755.

Giampietro, M. 2003. Multi-scale integrated analysis of agroecosystems. CRC Press, Boca Raton, Florida, USA.

Gitau, T., J. McDermott, D. Waltner-Toews, and G. Otieno. 1998. Second interim report on an integrated assessment of agricultural communities in the Kenyan highlands. Network for Ecosystem Sustainability and Health, Kitchener, Ontario, Canada.

Gitau, T., J. McDermott, D. Waltner-Toews, J. M. Gathuma, E. K. Kang, V. W. Kimani, J. K. Kilungo, R. K. Muni, J. M. Mwangi, and G. Otieno. 2000. Agro-ecosystem health: principles and methods used in high-potential tropical agroecosystem. In M. A. Jabbar, D. G. Peden, M. A. M. Saleem, and H. Li Pun, editors. Agroecosystems, natural resources management and human health related research in East Africa: case studies. International Livestock Research Institute, Nairobi, Kenya. Available online at

http://www.ilri.cgiar.org/InfoServ/Webpub/Fulldocs/ Aesh/Agro.htm.

Gunderson, L., and C. S. Holling, editors. 2002. Panarchy: understanding transformations in human and natural systems. Island Press, Washington, D. C., USA.

Hogan, P. 2003. The mind and its stories: narrative universals and human emotion. Cambridge University Press, New York, New York, USA.

Holling, C. S. 1986. The resilience of terrestrial ecosystems: local surprise and global change. Pages 292-317 in W. M. Clark and R. E. Munn, editors. Sustainable development in the biosphere. Cambridge University Press, Cambridge, UK.

Kay, J. J. 1997. Some notes on the ecosystem approach: ecosystems as complex systems. Pages 69-98 in T. Rowley and G. Gallopin, editors. Integrated conceptual framework based on complex systems theories. Working Document 167. Centro
Internacional de Agricultura Tropical, Cali, Colombia.

Kay, J. J. 2000. Ecosystems as self-organizing holarchic open systems: narratives and the second law of thermodynamics. Pages 135-160 in S. Jorgensen and F. Muller, editors. Handbook of ecosystem theories and management. CRC Press, Boca Raton, Florida, USA.

Kay, J. J., and E. D. Schneider. 1994. Embracing complexity, the challenge of the ecosystem approach. Alternatives 20(3):32-38.

Kay, J. J., H. A. Regier, M. Boyle, and G. Francis. 1999. An ecosystem approach for sustainability: addressing the challenge of complexity. Futures 31 (7):721-742.

Koestler, A. 1969. Beyond atomism and holism: the concept of the Holon. Pages 192-232 in A. Koestler and J. R. Smythies, editors. Beyond reductionism. Hutchinson, London, UK.

Koestler, A. 1978. Janus: a summing up. Hutchinson, London, UK.

Lehane, L., and R. J. Lewis. 2000. Ciguatera: recent advances but the risk remains. International Journal of Food Microbiology 61(2/3):91-125.

Murray, T. P., J. J. Kay, D. Waltner-Toews, and E. Raez-Luna. 2002 Linking human and ecosystem health on the Amazon frontier: an adaptive ecosystem approach. Chapter 23 in A. A. Aguirre, R. S. Ostfeld, C. A. House, G. M. Tabor, and M. C. Pearl, editors. Conservation medicine: ecological health in practice. Oxford University Press, New York, New York, USA. Available online at http://www.fes.uwaterloo.ca/u/jjkay/pubs/consmed/

Olsson, P., C. Folke, and T. Hahn. 2004. Socialecological transformation for ecosystem management: the development of adaptive co-management of a wetland landscape in southern Sweden. Ecology and Society 9(4): 2. [online] URL:

http://www.ecologyandsociety.org/vol9/iss4/art2.

Pretty, J., I. Guijt, I. Scoones, and J. Thompson. 1995. A trainer's guide for participatory learning and action. International Institute for Environment and Development, London, UK. 
Ravetz, J. 1999. What is post-normal science. Futures 31:647-653.

Rowley, T. , G. Gallopin, D. Waltner-Toews, and E. Raez-Luna. 1997. Development and application of an integrated conceptual framework to tropical agroecosystems based on complex systems theories: Centro Internacional de Agricultura Tropical-University of Guelph Project. Ecosystem Health 3:154-161.

Smit, B., D. Waltner-Toews, D. Rapport, E. Wall, G. Wichert, E. Gwyn and J. Wandel. 1998. Agroecosystem health: analysis and assessment; the report of the Agroecosystem Health Project. University of Guelph, Faculty of Environmental Sciences, Guelph, Ontario, Canada.

Ulanowicz, R. 1997. Ecology, the ascendent perspective. Columbia University Press, New York, New York, USA.

Walters, C. 1986. Adaptive management of renewable resources. Macmillan, New York, New York, USA.

Waltner-Toews, D., M. Bunch, C. Neudoerffer, M. Parkes, and H. Venema. 2004a. Championing ecosystem sustainability and health: a profile and tribute to the life and work of James Kay (1954-2004). EcoHealth 1(4):334-339. Available online at:

http://www.ecohealth.net/pdfs/EcoHealth1 4 p334-339 Profile.pdf.

Waltner-Toews, D., J. J. Kay, and N. M. Lister, editors. In press. The ecosystem approach: complexity, uncertainty and managing for sustainability. Columbia University Press, New York, New York, USA.

Waltner-Toews, D., J. J. Kay, T. Murray, and C. Neudoerffer. 2004b. Adaptive Methodology for Ecosystem Sustainability and Health (AMESH): an introduction. Pages 317-349 in G. Midgley and A. E. Ochoa-Arias, editors. Community operational research: systems thinking for community development. Plenum/Kluwer Academic, New York New York, USA.

Waltner-Toews, D., J. J. Kay, C. Neudoerffer, and T. Gitau. 2003. Perspective changes everything: managing ecosystems from the inside out. Frontiers in Ecology and the Environment 1(1):23-25.
Waltner-Toews, D., C. Neudoerffer, D. D. Joshi, and M. S. Tamang. 2005. Agro-urban ecosystem health assessment in Kathmandu, Nepal: epidemiology, systems, narratives. EcoHealth 2(2):155-164.

Walker, B., S. Carpenter, J. Anderies, N. Abel, G. S. Cumming, M. Janssen, L. Lebel, J. Norberg, G.D.Peterson, and R. Pritchard. 2002. Resilience management in social-ecological systems: a working hypothesis for a participatory approach. Conservation Ecology 6(1): 14. [online] URL: http://www.consecol.org/vol6/iss 1/art14.

White, M., and D. Epston. 1990. Narrative means to therapeutic ends. W. W. Norton, New York, New York, USA.

White, M. 2003. Narrative practice and community assignments. International Journal of Narrative Therapy and Community Work (2):17-55. 